\title{
BASAL STERILE MUTANTS IN SPELTOID WHEAT
}

\author{
O. H. FRANKEL and A. S. FRASER
}

Wheat Research Institute, Christchurch, New Zealand

Received 16. i. 48

\section{INTRODUCTION}

Among a number of speltoids discovered in a crop of Yeoman II wheat in 1929-30, one plant was sterile in the basal floret of most spikelets. Its descendants throughout the years remained constant. Crossed with Yeoman II it gave an $\mathbf{F}_{2}$ segregation of I Yeoman : 2 basal-fertile heterozygous speltoids : I basal-sterile homozygous speltoid. When crossed with an unrelated vulgare variety, Victor, the homozygous speltoid fraction in the $F_{2}$ varied in its basal fertility from fertile to sterile, with all intermediate degrees of fertility. The intermediate basal sterility is expressed in two different ways : either all the heads of one plant are similar, with intermediate frequencies of basal-sterility; or the heads may differ, providing chimæra-like combinations of different sterility and fertility types. In later generations selection from this $F_{2}$ succeeded in extracting a basalfertile homozygous speltoid. This paper deals with the inheritance of basal fertility in these speltoids, and by implication in related forms of Triticum vulgare.

Two further speltoids with higher but variable sterility, which were recently obtained from A. T. Pugsley, Waite Agricultural Research Institute, Adelaide, enhanced the interest in the determination of fertility relationships in speltoids. These further types have not yet been studied.

\section{DESCRIPTION OF MAIN SPELTOID TYPES}

All the parents and $F_{1}$ included in this study form $2 \mathrm{I}$ bivalents during meiosis. No deletion was detected cytologically ( $c f$. Huskins, I946). This, together with the I : $2:$ I segregation of vulgare : heterozygous speltoid : speltoid referred to above, places these speltoids as series $a$ types ( $c f$. Huskins, l.c.). There was no evidence of structural hybridity in any of the $F_{1}$ s. Differences in chiasma frequencies between parents and $F_{1}$ s were of the order to be expected from environmental variation ( $c f$. Mather, I935).

Fig. I illustrates diagramatically the normal distribution of sterile and fertile florets in spikelets of the stable speltoid types. There are, however, exceptional spikelets in all types (pl. I). 
In selfed progenies of single plants grown in 1934-35, the following frequencies of fertile basal florets were obtained : basal-sterile speltoid 26-28 per cent., basal-fertile speltoid 86 per cent. There is, however, in general a good deal of fluctuation.

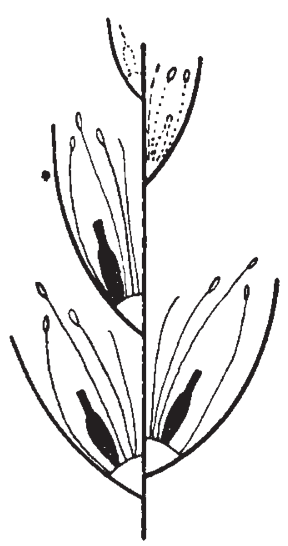

$\mathrm{St}_{\mathrm{f}}$

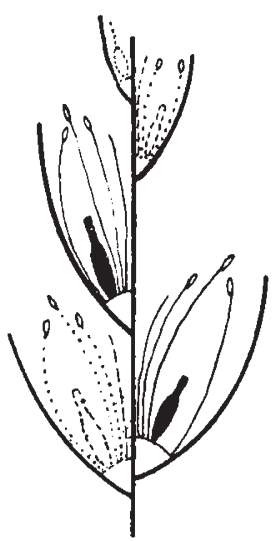

$\mathrm{St}_{1}$

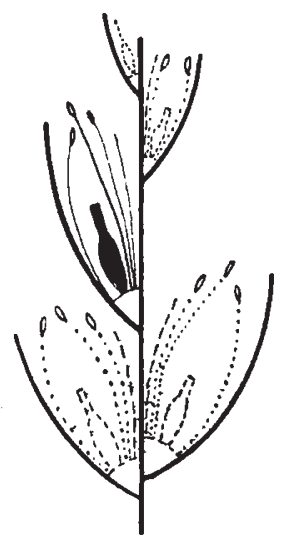

$\mathrm{St}_{2}$

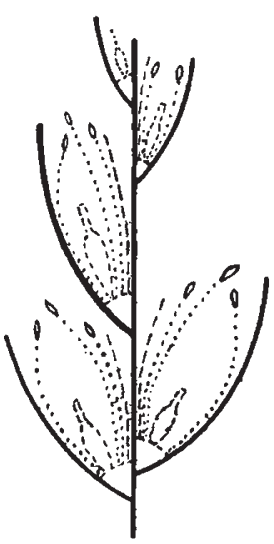

$\mathrm{St}_{\mathbf{8}}$

FIG. 1.-Spikelet types in speltoids. Florets drawn in outline are usually sterile but sporadically form grain. Florets drawn in black are normally fully fertile.

Ten ears of the basal-sterile speltoid were dissected shortly before flowering. As in the mature plant, the lemma was fully developed in each floret. The basal floret showed different degrees of development in the following proportions of spikelets :-

Fully developed

Palea missing .

Palea, androecium missing and sometimes gynoecium as well

I 5 per cent. $25, "$, . $60, "$,

Observations by Dr I. F. Phipps and Mr A. T. Pugsley generally confirm these sterility relationships in the abortive flowers of their semi-sterile speltoids.

The following symbols are used :-

V-Victor, normal Triticum vulgare variety.

Y-Yeoman, normal Triticum vulgare variety.

$\mathrm{St}_{1}$-homozygous speltoid, majority of basal florets sterile.

$\mathrm{St}_{\mathrm{f}}$-homozygous speltoid, majority of basal florets fertile.

$\mathrm{St}_{\mathrm{i}}$-homozygous speltoid, proportion of basal florets sterile.

$\mathrm{St}_{\mathrm{u}}$-homozygous speltoid, chimæra-like combinations of heads with complete basal fertility (as in $\mathrm{St}_{\bar{\xi}}$ ), complete basal sterility (as in $\mathrm{St}_{\mathbf{1}}$ ) and partial basal sterility (as in $\mathrm{St}_{\mathbf{i}}$ ) in the same plant. 


\section{RESULTS}

The $F_{2}$ data presented in the table and fig. 2 permit the following conclusions :-

(i) $\mathrm{St}_{1}$ and $\mathrm{Y}$ have a speltoid fraction in their $\mathrm{F}_{2}$ consisting only of $\mathrm{St}_{1}$, and therefore are apparently isogenic for basal sterility (cross I).

(ii) $\mathrm{St}_{\mathrm{f}}$ and $\mathrm{V}$ similarly are apparently isogenic for basal fertility (cross 2).

(iii) In crosses between these two groups, the speltoid fraction contains all grades of fertility (crosses 3-5).

(iv) If $\mathrm{Y}$ and $\mathrm{St}_{\mathbf{1}}$ were truly isogenic, then the segregations in the speltoid fractions in crosses 4 and 5 should be identical. However, the frequencies in the sterility classes are higher in cross 5 than in cross 4 .

(v) Similarly if $\mathrm{V}$ and $\mathrm{St}_{\mathrm{f}}$ were truly isogenic, the speltoid segregations in crosses 3 and 5 should be identical, which again is not the case.

Results in back and triple crosses confirm those quoted above.

TABLE

Segregation in $F_{2}$ of crosses $I-5$

(Percentages of fertility types in the speltoid fraction are shown in italics)

\begin{tabular}{|c|c|c|c|c|c|c|c|c|}
\hline \multirow{2}{*}{ Cross no. } & \multirow{2}{*}{ Parents } & \multirow{2}{*}{ vulgare } & \multirow{2}{*}{ Het. speltoid } & \multicolumn{4}{|c|}{ Speltoid } & \multirow{2}{*}{ Total } \\
\hline & & & & $\mathrm{St}_{\mathrm{f}}$ & $\mathrm{St}_{\mathrm{i}}$ & $\mathrm{St}_{\mathrm{u}}$ & $\mathrm{St}_{1}$ & \\
\hline I & $\mathrm{Y} \times \mathrm{St}_{1}$ & 366 & 814 & $\cdots$ & $\cdots$ & $\cdots$ & $\begin{array}{l}431 \\
100 \cdot 0\end{array}$ & 1611 \\
\hline 2 & $\mathrm{~V} \times \mathrm{St}_{\mathrm{f}}$ & 192 & 468 & $\begin{array}{l}235 \\
x 00 \cdot 0\end{array}$ & $\cdots$ & $\cdots$ & $\cdots$ & 895 \\
\hline 3 & $\mathrm{~V} \times \mathrm{St}_{1}$ & 284 & $5^{61}$ & $\begin{array}{c}112 \\
45.3\end{array}$ & $\begin{array}{l}69 \\
27 \cdot 9\end{array}$ & $\begin{array}{l}30 \\
14 \cdot 6\end{array}$ & $\begin{array}{l}3^{6} \\
Y 2 \cdot I\end{array}$ & $109^{2}$ \\
\hline 4 & $\mathrm{Y} \times \mathrm{St}_{\mathrm{f}}$ & 107 & 278 & $\begin{array}{l}89 \\
69 \cdot 0\end{array}$ & $\begin{array}{l}15 \\
I I \cdot 6\end{array}$ & $\begin{array}{l}19 \\
14.7\end{array}$ & $\begin{array}{l}6 \\
4 \cdot 6\end{array}$ & $5^{14}$ \\
\hline 5 & $\mathrm{St}_{\mathrm{f}} \times \mathrm{St}_{1}$ & $\cdots$ & $\cdots$ & $\begin{array}{c}173 \\
27 \cdot 2\end{array}$ & $\begin{array}{l}154 \\
24 \cdot 2\end{array}$ & $\begin{array}{r}234 \\
36 \cdot 8\end{array}$ & $\begin{array}{l}75 \\
11 \cdot 8\end{array}$ & 636 \\
\hline
\end{tabular}

\section{DISCUSSION}

Since basal sterility is phenotypically correlated with the speltoid character, it seems reasonable to consider linked modes of origin.

According to the theory of the origin of speltoids and the related fatuoids (Winge, 1924; Huskins, 1933; and recently reviewed by Huskins, I946), the common feature of series $a, \beta$ and $\gamma$ speltoids is the partial or complete deletion of the $\mathrm{G}$ chromosome, on which the epistatic genes $(\mathbf{S})$ which determine vulgare head characters are located. In the $\beta$ series the entire chromosome is missing; the 
series $\gamma$ has an observable deficiency, with every intergradation to the series $\alpha$ speltoids in most of which the deficiency is not cytologically detectable. This deletion allows the expression of hypostatic genes determining speltoid head characters. From the theory of the alloploid origin of hexaploid wheats it is deduced that the speltoid gene or gene complex is located upon the semi-homologous B chromosome (Winge, I924; Huskins, I946 ; McFadden and Sears, 1946). The series $\beta$ speltoids and fatuoids, which lack the $\mathrm{C}$ chromosome altogether, are proof that the speltoid complex is not located on the $\mathrm{C}$ chromosome.

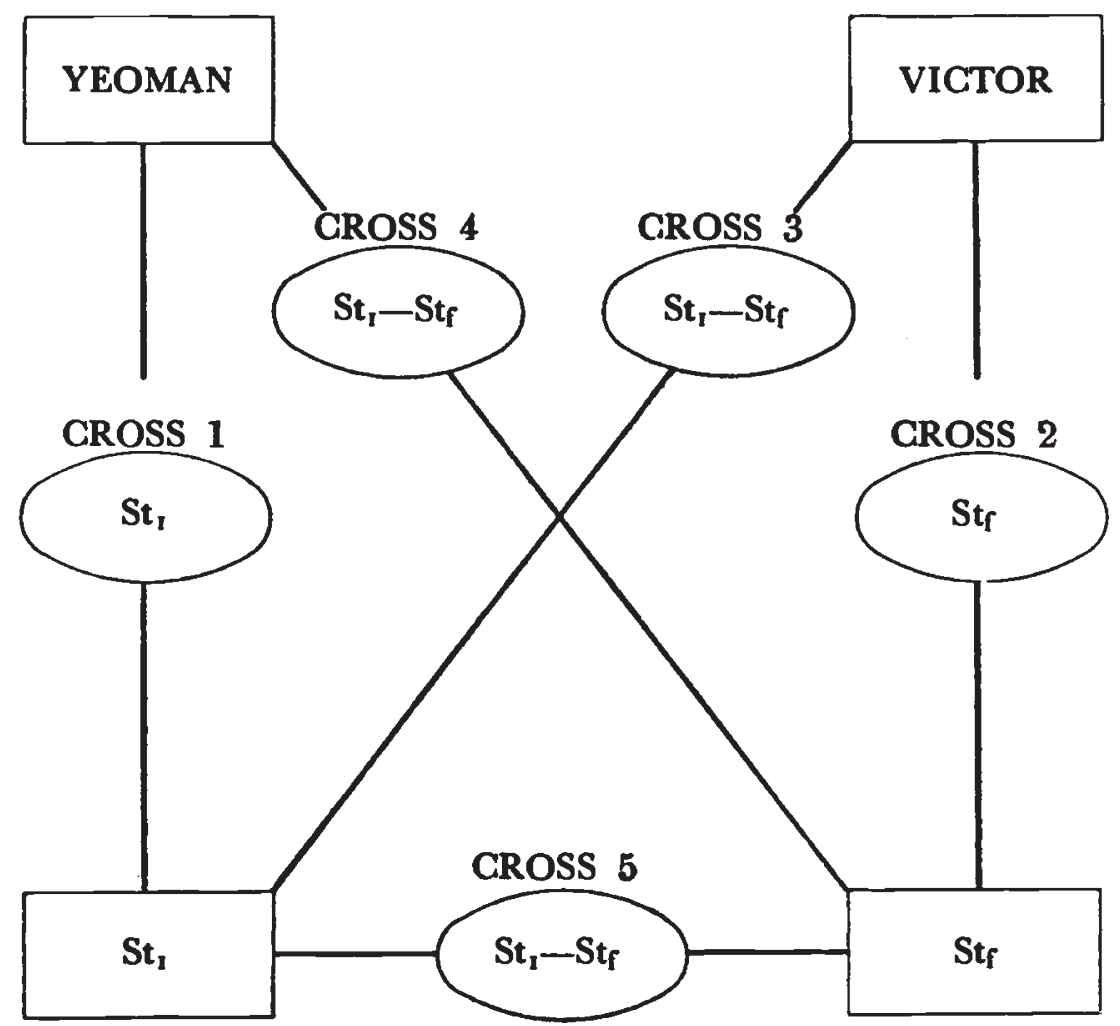

Fro. 2.-Basal fertility in crosses. Parents in rectangles and, in ovoids, fertility grades of the speltoid fractions in $\mathrm{F}_{2}$.

The observations summarised in (i-v) above present three distinct facts.

(a) The difference in basal fertility between vulgare and $\mathrm{St}_{1}$ speltoids. We suggest that this difference is caused by an epistatic gene or gene complex (F) linked to $(\mathrm{S})$ and included in an undetected deletion of the $\mathrm{C}$ chromosome responsible for the origin of the speltoid types.

(b) The difference in basal fertility between $\mathrm{Y}$ and $\mathrm{St}_{1}$ on one hand, and $\mathrm{V}$ and $\mathrm{St}_{\mathrm{f}}$ on the other hand. We propose that this be explained 
on the basis of gene differences with partial dominance of fertility $\left(G_{x} / g_{x}\right)$. The location of these genes cannot be defined but it is postulated that one or more $(\mathrm{G} / \mathrm{g})$ are located upon the $\mathrm{C}$ chromosome external to the deletion.

(c) The quantitative differences in basal fertility in the segregating speltoid fractions of the crosses 3-5 (table). We suggest that these are due to differences in the proportions of crossovers and noncrossovers between the breakage point of the deletion (D) and the gene or genes $(\mathrm{G} / \mathrm{g})$ which are located upon the $\mathrm{C}$ chromosome. On this view the chief difference between crosses 3 and 4 , viz. in the frequencies of $\mathrm{St}_{\mathfrak{f}}$, is due to the mode of origin of $\mathrm{St}_{\mathfrak{f}}$ which in cross 3 arises from crossing-over, in cross 4 from segregation. In cross 5 , which has two speltoid parents, and hence no crossing-over between $\mathrm{D}$ and $\mathrm{G} / \mathrm{g}$ all fertility classes arise from segregation.

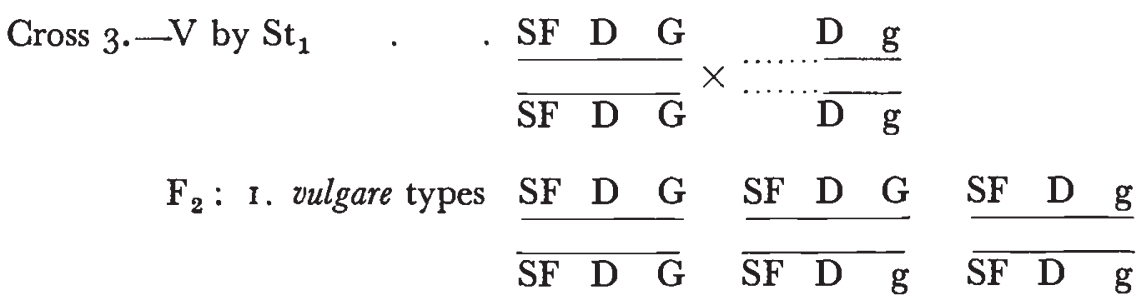

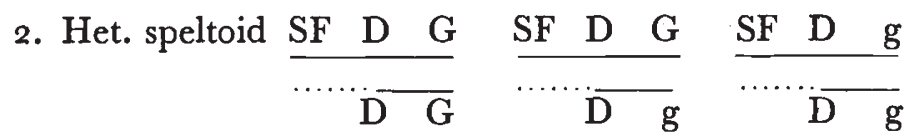

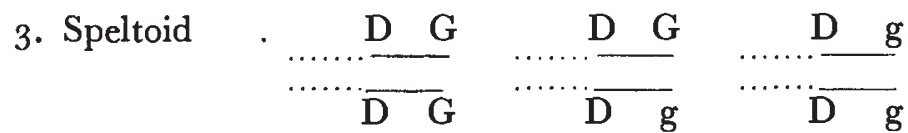

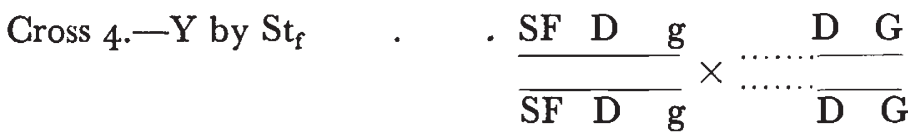

$F_{2}: 3$. Speltoid as in cross 3 except that some of the crossover types are now non-crossovers.

Cross $5 \cdot-\mathrm{St}_{\mathrm{f}}$ by $\mathrm{St}_{1}$

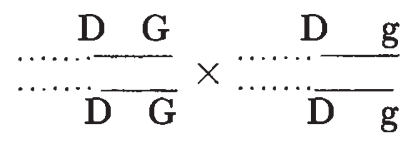

$F_{2}: 3$. Speltoids now all non-crossovers.

FIG. 3.- Segregation for basal sterility in crosses 3,4 and 5 , on the assumptions of one fertility complex $(\mathrm{F})$ in the speltoid deletion and of another complex $(\mathrm{G} / \mathrm{g})$, also located on the $\mathrm{C}$ chromosome.

The question must be asked as to the nature of what has been referred to as the gene complex for basal fertility $\left(G_{x} / g_{x}\right)$. Evidence 
is available from many simple, back and triple crosses, but the most direct comes from the cross $\mathrm{V}$ by $\mathrm{St}_{1}$, of which a large material was grown up to $F_{6}$. In this cross neither of the two parent genotypes was obtained in an $F_{2}$ of 107 plants which were tested in $F_{3}$. It is therefore likely that the minimum number of required genes is two. No concrete suggestions would be fruitful as to the number of genes actually involved, in view of the possibility of dominance in opposite directions and in view of the great difficulty of diagnosis imposed by fluctuation.

Selection, commenced in $F_{2}$, succeeded by $F_{5}$ in establishing a line with full fertility, which has since remained constant. Selection for basal sterility was not carried out as consistently and a homozygous line was not obtained in the limited periods during which selection was practised. The proportion of basal sterile plants was, however, rapidly increased.

The theory proposed above postulates that at least one gene for basal fertility $(\mathrm{G} / \mathrm{g})$ in addition to the gene or gene complex $(\mathrm{F})$ is situated upon the $\mathrm{C}$ chromosome. Where the further gene or genes for fertility are located cannot be defined. The location of another epistatic "normal" gene (F) upon the $\mathrm{C}$ chromosome, in addition to those previously recorded ( $c f$. Huskins, 1946), further emphasises the importance of this chromosome in the evolution of Triticum.

Basal sterility, although rare in the Hordea, is widespread in the Graminea as a whole. This in itself argues for its antiquity, and when, as in the basal-sterile speltoids, it is combined with an archaic character, it suggests an origin beyond its present generic confines. Yet the fact that among the many speltoid wheats reported so far only a few with basal sterility have been found, does not support the idea of a widespread occurrence of $g_{x}$ in Triticum vulgare. It remains to be seen whether $g_{x}$ is common in Yeoman, and whether it occurs in one or both of its parents.

The fact that basal sterility mutants occur raises the question as to the determination of basal fertility in the $\mathrm{A}$ and $\mathrm{B}$ chromosome sets. Typically both of these condition basal fertility. The mutant reported here tends to suggest that the $\mathrm{F}$ gene has taken charge of basal fertility to such an extent as to inactivate corresponding complexes in other sets.

\section{SUMMARY}

Sterility of the basal floret in a series a speltoid wheat is caused by genes hypostatic to elements included in the speltoid deletion of the $\mathrm{C}$ chromosome. It is suggested that at least some of the hypostatic genes are situated on the $\mathrm{G}$ chromosome of Triticum vulgare.

Acknowledgments.-We are greatly indebted to Dr C. D. Darlington, who read the manuscript, for valuable suggestions and criticisms, and to Mr J. B. Hair for his assistance in classifying most of the speltoid material used in this study. 

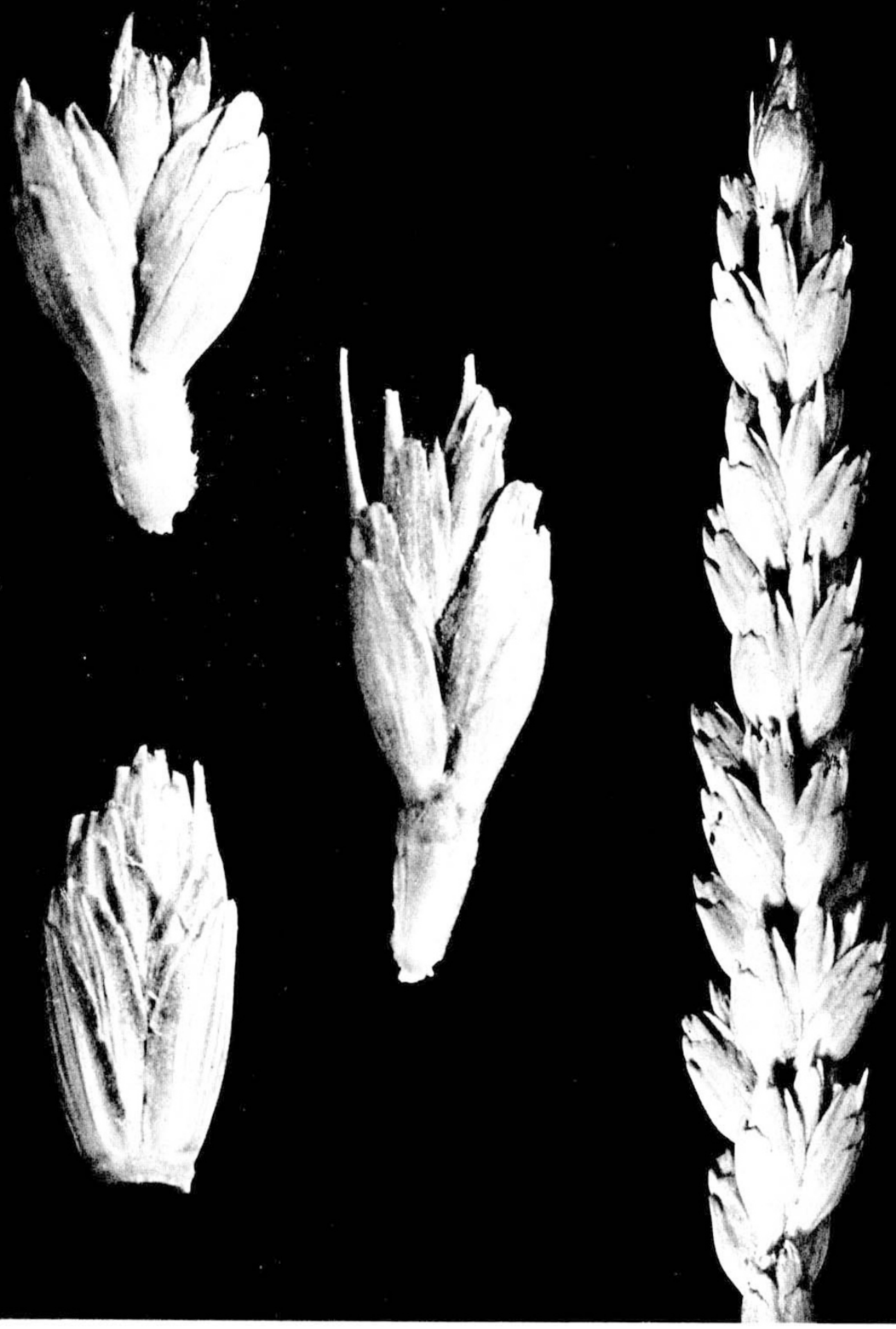


\section{REFERENCES}

HUSKINS, L. 1933 .

The origin and significance of fatuoids, speltoids and other aberrant forms of oats and wheat.

Proc. Worlds Grain Exhib. and Conf. II, 45-49.

HUskins, $\mathbf{L} .1946$.

Fatuoid, speltoid and related mutations of oats and wheat.

Bot. Rev. 12, 457-514.

McFADDEN, E. S., AND SEARS, E. R. 1946.

The origin of Triticum Spelta and its free threshing hexaploid relatives.

7. Hered. 37, 81-89, 107-116.

MATHER, K. 1935 .

Chromosome behaviour in a triploid wheat.

Z.f. Zellforsch. 23, 11 7-1 38 .

WINGE, $\oslash$. I924.

Zytologische Unterschungen über Speltoide und andere mutantenähnliche Aberranten beim Weizen.

Hereditas 5, 21 4-286. 